\title{
Building Concrete Corrosion expansion Stress and Internal Crack Analysis in Consideration of Protective Layer Thickness Impact
}

\author{
Li ZHENG ${ }^{1}$ a \\ ${ }^{1}$ Department of Information Engineering ,Sichuan College of Architectural Technology, \\ Deyang, 618000, China \\ aemail: zhengliscy@163.com
}

\section{Keywords: Corrosion Expansion; Protective Layer; Concrete; Internal Crack Analysis}

\begin{abstract}
Section loss and strength reduction of rebar, concrete section damage and adhesive performance degradation between rebar and concrete cased by corrosion of rebar are major factors for reduction column bearing capacity. It studies major reasons for failure of domestic reinforced concrete durability, analyzes corrosion mechanism in non-cracked and cracked states and major factors of concrete corrosion, puts forwards anti-corrosive policy for rebars in concrete structure and lays the foundation to strengthen durability of the structure and prolong the service life.
\end{abstract}

\section{Introduction}

Chlorine ion corrosion and concrete solidification will induce corrosion of rebar. Strength of rebar is weakened and adhesive performance between rebar and concrete is reduced after the rebar is corroded, which are the major reasons of reduction of structure bearing capacity. As a result, a large number of engineering structures are damaged before the designed service term expires. As corrosion cycle of rebar in the concrete is relatively long in natural conditions, the method to accelerate corrosion by impressed current is commonly used. Unomoto uses peripheral copper electrode to accelerate corrosion of rebar. The control current density is $200-630 \mathrm{uA} / \mathrm{cm}^{3}$ and test piece is immersed in $\mathrm{NaCl}$ solution with concentration of $5 \%$ to study corrosion degradation mechanism of reinforced concrete beam. Some researchers use peripheral stainless steel electrode to accelerate corrosion with control current density is $2000 \mathrm{uA} / \mathrm{cm}^{3}$. Test piece is immersed in salt solution to study adhesive performance of corroded-and-cracked reinforced concrete beam.

\section{Natural electrochemical corrosion}

Corrosion of rebar in reinforced concrete structure is mainly electrochemical corrosion, which is because the water in the interspace of concrete exists in form of saturated calcium hydroxide solution. There is some sodium hydroxide and calcium hydroxide in the solution and the $\mathrm{pH}$ value of the solution is 12.5. In such highly alkaline environment, passive film forms on the surface of rebar, which is a kind of hydrated oxide $\left(\mathrm{nFe}_{2} \mathrm{O}_{3} \cdot \mathrm{mH}_{2} \mathrm{O}\right)$ with thickness of $2 \times 10^{-9}-6 \times 10^{-9} \mathrm{~m}$ that can prevent further corrosion of rebar. However, passive film on the surface of rebar is broken and activated, the rebar is easy to be corroded. Electrochemical mechanism of corrosion reaction on the activated rebar surface is, when there is water existing on the surface of rebar, anodic reaction of iron ionization and cathodic reaction of oxygen reduction in solution happen mutually at the same speed. The equations are as follows:

Anodic reaction $2 \mathrm{Fe}-4 \mathrm{e}^{-} \rightarrow 2 \mathrm{Fe}_{2}$

Cathodic reaction $\mathrm{O}_{2}+2 \mathrm{H}_{2} \mathrm{O}+4 \mathrm{e}^{-} \rightarrow 4 \mathrm{OH}^{-}$

The complete reaction in corrosion process is the combination of anodic reaction and cathodic reaction. Ferrous hydroxide precipitates on the surface of rebar and the equation is:

$2 \mathrm{Fe}+\mathrm{O}_{2}+2 \mathrm{H}_{2} \mathrm{O} \rightarrow 2 \mathrm{Fe}_{2}+40 \mathrm{H}^{-} \rightarrow 2 \mathrm{Fe}(0 \mathrm{H})_{2}$

$4 \mathrm{Fe}(\mathrm{OH})_{2}+\mathrm{O}_{2}+2 \mathrm{H}_{2} \mathrm{O} \rightarrow 4 \mathrm{Fe}(\mathrm{OH})_{3}$

The compound becomes ferric hydroxide $\mathrm{Fe}(\mathrm{OH}) 3$ after it is dissolved and oxidized and further becomes $\mathrm{nFe}_{2} \mathrm{O}_{3} \cdot \mathrm{mH}_{2} \mathrm{O}$ (red rust). The incompletely oxidized compound becomes ferriferrous 
oxide $\mathrm{Fe}_{3} \mathrm{O}_{4}$ (black rust). As a result a rust layer is formed on the surface of rebar. Volume of red rust can be 4 times and volume of black rust can be twice of the original volume. Rust volume expands, which causes pressure to surrounding concrete and make concrete crack in direction of rebar so that the protective layer comes off and crack and loss of protective layer further induce the fiercer corrosion of rebar.

\section{External coating of concrete}

(1) Polymer modified cement mortar. Speaking of new concrete facing material developed in recent years, polymers are mixed into cement mortar in form of emulsion, which greatly improves compactness and adhesion of cement mortar layer. The durability can be consistent with base concrete. China already has acrylic-emulsion mortar and neoprene-emulsion mortar and now some new varieties come into being, such as $\mathrm{FC}-01$ and $\mathrm{RP}-\mathrm{w}$ series anti-corrosive mortars developed by Architecture Research Institution of Ministry of Metallurgical Industry. Polymer modified cement mortar layer is many highly corrosive environments where many salts (Chlorine salts and sulfates) exist, such as industrial building, saline-alkali soil building, oceanographic engineering and other large amount of restoration works applied in existing buildings. After all, polymer modified cement mortar is cement-based material so it does not resist acid in principle. Therefore, it is not feasible to strongly acidic environment.

(2) Penetrative coating. When concrete surface is covered with penetrative coating, it can react chemically with constituents of concrete and block the interspace or it can polymerize itself to form consecutive hydrophobic film. Penetrative coating material can penetrate $3-5 \mathrm{~mm}$ inside the concrete to form a special protective layer, which can effectively prevent external corrosive mediums entering the concrete and protect the rebar from corrosion. There is another kind of coating called impregnating coating, which is similar to and different form penetrative coating. Such impregnating coating penetrates into the concrete by impregnating monomers of polymer and polymerizing them inside the concrete to for a waterproof protective layer. However, such impregnating coating can be applied in small components only.

(3) Concrete surface coating. Cover the surface of reinforced concrete with anti-corrosive coating to prevent penetration of harmful mediums and keep alkalinity and structure of the concrete so that reinforced concrete is free from damage. Anti-corrosive coating is one of the effective and common methods. In small area of highly corrosive environment, surface coating protective measure is the first choice.

\section{Calculation of corrosion expansion force}

As transverse rebar (mainly refer to stirrup) exists, which has restraint effect on concrete, when concrete is cracked, its adhesive strength will continue to increase in existence of transverse rebar. On such premise, assume: when the concrete beam component is not cracked for corrosion expansion, transverse rebar has no impact on corrosion expansion force; when the concrete is cracked, stirrups provide restraint effect on concrete. Large amount researches indicate impact of corrosion of rebars in concrete component on component bearing capacity is reflects in the following aspects: (1) reduce section of rebar and degrade mechanical performance; (2) corrosion expansion force makes concrete crack even come off and causes damage to concrete section; (3) corrosion of rebar degrades the cooperative working capacity with the concrete;

Based on the analysis above, calculation of small eccentric compressed column bearing capacity of corroded reinforced concrete raised in the thesis is as follows:

$$
\left\{\begin{array}{l}
N=k_{c} f_{c} b_{c} x+k_{y}^{\prime} f_{y}^{\prime} A_{s c}^{\prime}-k_{b} \sigma_{s} A_{s c} \\
M=N e=k_{c} f_{c} b_{c} x\left(x / 2-a_{s}^{\prime}\right)-k_{b} k_{y} \sigma_{s} A_{s c}\left(h_{0}-a_{s}^{\prime}\right)
\end{array}\right.
$$

Where $e=x / 2-\alpha_{s}^{\prime}-e_{0} ; e_{0}$-initial eccentric distance; $\alpha_{s}, \alpha_{s}^{\prime}$-distance between center of rebar to concrete surface; $b_{c}, h_{c}$ and $h_{0}$-component section parameter in consideration of 
section damage, $h_{0}=h_{c}-\alpha_{s} ; f_{c}$ and $k_{c}$-compressive strength of concrete column and decreasing coefficient of concrete strength; $k_{y}$ and $k_{y}^{\prime}$-decreasing coefficient of concrete yield strength; $k_{b}$ - cooperative working coefficient between rebar and concrete; $\sigma_{s}$ and $x$ - rebar stress in tensile zone and depth of concrete compression zone; $A_{s c}$ and $A_{s c}^{\prime}$-section area of corroded rebar. Where $\mathrm{A}_{\mathrm{st}}$ is total section area of stirrup on the section; $\mathrm{E}_{\mathrm{s}}$ is elasticity modulus of steel; a is parameter (take 0.1 ); $\mathrm{d}_{\mathrm{st}}$ is stirrup diameter; $\mathrm{w}$ is width of crack caused by corrosion expansion. It can be seen that, when crack width is zero, stirrup has no effect on rebar. This model is calculated from rectangular enclosed box and computer model is unfolded board model so the effect of stirrup on concrete is

Kinetic equation of vertical grinder roll grinding system can be established through Lagrange method. This system is non-conservative system. Non-conservative Lagrange equation expression:

$$
\frac{d}{d t}\left(\frac{\partial T}{\partial \dot{q}_{i}}\right)-\frac{\partial T}{\partial q_{i}}+\frac{\partial U}{\partial q_{i}}=Q_{i},(i=1,2, \cdots, n)
$$

Where, $T, U$ is kinetic energy and potential energy of the system; $q_{i}, \dot{q}_{i}$ is generalized coordinate and generalized velocity; $Q_{i}$ is generalized exciting force outside the system and $t$ is time. Generalized coordinates of the system shall be established first of all. Then kinetic energy $T$ and potential energy $U$ of the system shall be figured out. Kinetic energy $T$, potential energy $U$ and generalized exciting force $Q_{i}$ shall be introduced into Lagrange equation to establish kinetic equation of the system. In bar system model, components such as girder in the model, column and shear wall are elementary units and mass of the member bar concentrates on model node. Each node has independent horizontal, vertical linear displacement and rotary movement angle displacement. According to the model, partial internal force and deformation state of each member bar, change of structural strength, rigidity and mass reflecting whole process and sequence for each member bar to come into elastic-plastic stage under earthquake effect and its damage degree can be figured out. Though the model has many member bars and much degree of freedom and computational effort is huge, it considers the process in which each member bar comes into plastic stage one by one carefully and comprehensively and the calculation results are accurate. The model applies to strong column and weak beam type model and combination model.

\section{Calculations for parameters of concrete protective layer}

The yield strength of rusted rebar generally takes the actually measured value or otherwise it is recommended to select the calculation formula of the yield strength of rusted rebar in Literature [10] to determine $k_{y}$. Since the rebar's concrete mechanical property before and after corrosion, according to relevant data, display tiny changes, we can temporally make the concrete strength impact factor on rebar corrosion as $k_{c}=1$. At present, studies on adhesive property between rusted rebar and concrete mainly focus on pull-out tests of rusted members, accompanied with minor beam or half-beam tests. In beam test, the load-carrying state of beam structures is stimulated, which is relatively more coordinate to real load-carrying state. As there is no study now on the coordination working property of rusted rebar and concrete, we adopted the regression coordination working factor of beam test results in literatures, $k_{b}$, with appropriate amendments taken into consideration when applied to column members. Coordination working factor from regression of test results in literatures is:

$$
k_{b}=\left\{\begin{array}{lc}
1 & \rho<1.5 \% \\
1-(2.742 \rho-4.068) / 100
\end{array}(3)\right.
$$

$\rho$---mass loss rate of rusted rebar. It is recommended to adopt the following formulas to calculate the sizes of geometry damage sections: 


$$
\left\{\begin{array}{l}
h_{c}=h-\sum_{i=1}^{2} \alpha_{h c} c_{i} \\
b_{c}=b-\sum_{i=1}^{2} \alpha_{b c} c_{i}
\end{array}\right.
$$

\section{conclusion}

Both domestic and overseas specialists and scholastics have paid high attention to rebar corrosion and considerable progresses have been made through many scholastics' efforts. However, since the condition of rusted rebar is quite complicated, accurate calculation models are extremely hard to establish. Therefore, there still are many problems to be solved. As for analysis methods: as of now, studies on three constitutive relations, rusted concrete, rusted rebar and adhesive property between rusted concrete and rebar, are far from perfect while theses three relations are the basis to carry out mechanical analysis on rusted rebar of reinforcement concrete structures; the ambiguity of there three relations has led to the lacking of systematic theory basis of rusted rebar, thus further studies are required in this aspect.

\section{Reference}

[1] Song, X., and Geng, Y. (2014). Distributed Community Detection Optimization Algorithm for Complex Networks. Journal of Networks, 9(10), 2758-2765.

[2] Pahlavan, K., Krishnamurthy, P., and Geng, Y. (2015). Localization Challenges for the Emergence of the Smart World, Access, IEEE, 3(1), 1-11.

[3] He, J., Geng, Y., Wan, Y., Li, S., and Pahlavan, K. (2013). A cyber physical test-bed for virtualization of RF access environment for body sensor network. Sensors Journal, IEEE, 13(10), 3826-3836.

[4] Lv Z, Tek A, Da Silva F, et al. Game on, science-how video game technology may help biologists tackle visualization challenges[J]. PloS one, 2013, 8(3): 57990.

[5] Su T, Wang W, Lv Z, et al. Rapid Delaunay triangulation for randomly distributed point cloud data using adaptive Hilbert curve[J]. Computers \& Graphics, 2016, 54: 65-74. 